Purdue University Purdue e-Pubs

$11-7-1985$

\title{
Normal Incidence Absorption Properties of Single Layers of Elastic Porous Materials
}

J Stuart Bolton

Purdue University, bolton@purdue.edu

Follow this and additional works at: http://docs.lib.purdue.edu/herrick

Bolton, J Stuart, "Normal Incidence Absorption Properties of Single Layers of Elastic Porous Materials" (1985). Publications of the Ray W. Herrick Laboratories. Paper 169.

http://docs.lib.purdue.edu/herrick/169

This document has been made available through Purdue e-Pubs, a service of the Purdue University Libraries. Please contact epubs@purdue.edu for additional information. 
NORMAL INCIDENCE ABSORPTION PROPERTIES OF SINGLE

LAYERS OF ELASTIC POROUS MATERIALS

\author{
J.S. Bolton \\ Ray W. Herrick Laboratories \\ Purdue University \\ West Lafayette, IN 47907
}

Paper presented at the lloth meeting of the Acoustifal society of America, Nashville, Tennessee, 4-8 November, 1985. 
Recently a theory has been developed which describes wave propagation in relatively stiff, partially reticulated polyurethane foams, the type most commonly used in noise control applications [J.S. Bolton and E. Gold, J. Acoust. Soc. Am. Suppl. 1 77, S59 (1985)]. A high impedance wave associated with the bulk mechanical properties of the foam matrix is usually significantly excited in these materials. As a consequence the acoustical performance of $f$ inite depth layers of foam of this type is very sensitive to the boundary conditions which apply at the front and rear layer surfaces. specifically, it will be shown in this paper that the action of a film facing is dependent on how it is attached to the foam layer. In addition it will be demonstrated that a small gap, e.g., l mm, separating a foam layer from a hard backing can increase the low frequency absorption dramatically. A similar effect occurs when a film facing is not bonded directly to the surface of a foam layer but is separated from it by a thin air gap. This work has suggested an arrangemant for enhancing the low frequency absorption of thin foam layers. 


\section{SLIDE 1}

This paper follows on from one presented at the logth meeting of the Acoustical Society of America held in Austin, April 1984 [1]. That paper described the development of a theory intended to model wave propagation in acoustical foam. of the type normally used in noise control applications. In that paper theoretical predictions were compared with measured surface normal impedances of finite depth foam layers in two configurations, and the agreement was found to be reasonable. A significant feature of that work was the quantitative agreement of theory and experiment in the case of filmfaced foams, apparently the first time that this had been achieved. The present paper focuses on the acoustic absorption properties of foam layers, and in particular, on the effects of front and rear surface boundary conditions. All the results presented are theoretical calculations based on the previously developed theory. The theory is fully described in the author's Ph.D. Thesis [2].

\section{SLIDE 2}

The type of foam being considered here is "relatively stiff" and "partially reticulated". In this description, relatively stiff refers to foam whose in vacuo bulk modulus of elasticity is greater than that of air. In partially reticulated foam the individual polyhedral cells are partially closed by membranes remaining after the expansion phase. It is foams having these characteristics which are most frequently used in noise control applications. The major implication of the partial reticulation is that the air path through 
the material is made relatively tortuous, although it remains continuous (as opposed to closed cell foams in which there is no continuous air path).

Previous theoretical work has been concentrated primarily on fully reticulated foam (i.e., foam with fully open cells): see, for example, Lambert $[3,4]$. In this type of foam the residual cell membranes which remain after manufacture are removed by chemical or other means. This additional treatment makes these foams relatively expensive and consequently they are used primarily in specialized applications: e.g., to line anechoic chambers. Research has indicated that the bulk mechanical properties of the solid phase of this type of foam play only a minor part in determining the foam's behavior; rather it is essentially fixed by macroscopic fluidacoustical parameters such as flow resistance, porosity and, to a much smaller extent, the structure factor (since the latter is only slightly greater than unity in fully reticulated foams) $[3,4]$. In contrast the acoustical properties of partially reticulated foams are to a large extent determined by the bulk mechanical properties of the foam: i.e., the bulk density, bulk modulus of elasticity and the loss factor $[1,2]$.

\section{$\underline{\text { SLIDE } \underline{3}}$}

This slide was included in the Austin presentation and shows the calculated effect of the rear surface boundary condition on the normal incidence absorption coefficient of a one inch thick foam layer. It is intended that this slide illustrate the fact thati re- 
latively stiff, partially reticulated foam is very sensitive in its performance to apparently small changes in boundary conditions; this is true to a much greater extent than in the case of glass $f$ iber or fully reticulated foams. It should be emphasized that the only difference between the two configurations is the introduction in one case of a $1 \mathrm{~mm}$ air gap between the rear surface of the foam and the hard backing material. This change has the effect of lowering the frequency of the first absorption peak by a factor of five, from approximately $1600 \mathrm{~Hz}$ to $350 \mathrm{~Hz}$, a much larger effect than intuition would suggest. This behavior will be explained in the following, and also included are demonstrations of similar effects which occur when an air space is introduced between a film facing material and the foam layer.

\section{$\underline{\text { SLIDE }} \underline{4}$}

This slide summarizes very briefly the development of a theoretical model for one-dimensional wave propagation in elastic porous materials. The development does not include the effects of the bulk shear stiffness of the foam, and hence, predictions based on the theory are limited to the case of normally incident sound.

One proceeds by writing one-dimensional continuity and force equations for both phases of the foam: i.e., the solid part (referred to here as the "frame"), and the interstitial air. From these equations it is a straightforward matter to derive fourth order wave equations governing the four field variables of principal interest: the frame velocity, the locally averaged interstitial; air 
velocity, the normal stress in the frame, and the interstitial air pressure. The solution for each of these quantities is of the type shown on the slide for the frame velocity and consists of forward and backward going waves of two types, often referred to as the frame wave and the airborne wave. These two wave types are distinguished by their different propagation factors $\gamma_{1}$ and $\gamma_{2}$. It may be argued that this terminology is inappropriate since both waves appear in both phases of the foam. However, it is often true that the character of one wave type is essentially determined by the bulk mechanical properties of the frame while the character of the other wave is determined by the fluid-acoustical properties of the foam: e.g., the flow resistance, porosity and structure factor. In some geophysical applications these waves are also referred to as the fast and slow waves.

Solutions for the amplitudes of the various wave components in a layer of foam depend on the front and rear surface boundary conditions in any situation, and once the wave amplitudes have been determined it is easy to calculate the layer's surface normal impedance, which in turn may be used to calculate the reflection and absorption coefficients. It should be remembered that the theory that was used to calculate the examples shown in this paper is specifically appropriate to relatively stiff, partially reticulated foam; the assumptions underlying the theory are documented fully in reference [2]. 


\section{$\underline{\text { SLIDE }} \underline{5}$}

This and the next slide illustrate the boundary conditions which are likely to apply at the front surface of a foam layer. On each slide is a greatly exaggerated cross-section of a surface element ( $x$ greater than zero being the. direction into the foam). The frame in all cases is shaded. In addition, the subscript 1 is used to indicate frame properties while the subscript 2 identifies variables related to the interstitial air.

At an open surface the normal stress in the friame, $p_{m}$, and the pressure of the interstitial air, $p_{a}$, must be equal to the pressure in the exterior medium in order to avoid infinite accelerations at the surface. In the case of a porous medium having a surface porosity $h$ (which will be assumed here to equal the volume porosity), the force per unit area on the solid component is $p_{1}=p_{m}(l-h)$ and on the air component $p_{2}=p_{a} h$. Thus at the open surface $p_{1}=p(l-h)$ and $p_{2}=p h ;$ these are the force conditions.

The velocity boundary condition is derived from continuity considerations, and it requires that the total volume velocity per unit area be conserved at the surface. This is expressed as $\mathrm{v}=\mathrm{v}_{1}(\mathrm{l}-\mathrm{h})+\mathrm{v}_{2} \mathrm{~h}$, where $\mathrm{v}$ is the normal velocity in the external field. Note that there are no individual conditions to be met by $v_{1}$ and $\mathrm{v}_{2}$

When a membrane is continuously bonded to the front surface of the foam it is necessary to write an equation of motion for it.as well. In this case the difference in force per unit area across the 
film is balanced by the inertial force resulting from the membrane's motion. On the exterior face, the force per unit area is simply $p$, while on the foam side the force per unit area is $p_{m}(1-h)+p_{a} h$ which can be written as $p_{1}+p_{2}$. The inertial force generated by the membrane is $m_{s} d v / d t$ (where $v$ is the membrane velocity, which must also be equal to the external air velocity, and $\mathrm{m}_{\mathrm{s}}$ is the membrane mass per unit area). When specialized to a single frequency, the force balance becomes, $p-p_{1}-p_{2}=j \omega_{m_{s}} v$.

\section{SLIDE $\underline{6}$}

The first figure on slide 6 illustrates the velocity boundary condition which applies at a surface with a bonded membrane. It is normally assumed that such films are not flexible on the scale of a pore dimension. Thus the action of the membrane when bonded to the foam is to force the frame velocity and the interstitial air velocity to be equal and to be the same as the membrane velocity which in turn is equal to the normal surface velocity in the external field. Thus at this type of surface individual conditions do apply to both $v_{1}$ and $v_{2}$.

The situation is quite different when the membrane is not bonded to the foam but is separated from it by a small air gap. In this case, at the foam surface (i.e., at $x=\Delta$ ) the frame and air velocities, $v_{1}$ and $v_{2}$, are no longer constrained to be the same: i.e., a volume velocity condition applies. As will be shown in slides 7 and 8 this has important consequences for the surface normal impedance. 


\section{SLIDE 7}

The surface normal impedance is the ratio of pressure to normal velocity into the surface at $x=0: i . e ., z=p / v$. At an open surface the surface normal impedance, designated here as $z_{0}{ }^{\prime}$ can be written as shown (since $\mathrm{v}=\mathrm{v}_{1}(1-\mathrm{h})+\mathrm{v}_{2} \mathrm{~h}$ and $\mathrm{p}=\mathrm{p}_{1} /(1-\mathrm{h})=\mathrm{p}_{2} / \mathrm{h}$ ). This result indicates that the open surface impedance is comprised of the frame and interstitial air partial impedances $\left(z_{1}\right.$ and $z_{2}$ ' respectively) added in parallel (and weighted by the appropriate porosity factors). Therefore, when the impedances of the two components are significantly different, the overall impedance will be largely determined by the smaller of the two. In practice, the frame impedance is much higher than the air path impedance, and this is exaggerated by the porosity weighting, $h$ typically being greater than 0.9. Thus, crudely speaking, the scale of the impedance of an open faced layer is largely determined by the impedance the porous component alone.

\section{$\underline{\text { SLIDE } 8}$}

When the surface of the foam is sealed by an impermeable membrane the impedance is quite different. In this case it is easy to show that the surface normal impedance is as written on the slide. Thus the frame and air component impedances add in series (along with the mass reactance of the membrane itself). This is true even if the mass of the membrane is negligibly small. Thus the action of a bonded membrane is not simply to add mass, but rather to alter the way the surface normal impedance is formed. If, as is usually.the 
case in relatively stiff, partially reticulated foams, $z_{1}$ is much greater than $z_{2}$, then the normal impedance of the surface is essentially that of the frame component added to the membrane mass reactance.

\section{SLIDE $\underline{9}$}

When a membrane is separated form the foam surface by a small air gap, the surface normal impedance can be shown to be the open surface impedance in series with the membrane reactance (in the limit when the air gap thickness becomes negligibly small). That is, the surface normal impedance in this configuration is essentially that of the air component of the foam in series with the membrane reactance. In practice, then, the impedance in this configuration is much smaller than in the case of a bonded membrane.

\section{$\underline{\text { SLIDE } 10}$}

The ideas introduced in the last several slides are demonstrated by the examples shown here. Plotted are the surface normal impedances for the three cases indicated (in all three the foam Iayer is assumed bonded to the hard backing). The foam layer thickness is $25 \mathrm{~mm}$ and the model parameters used in the theory of Chapter 6 reference [2] are: bulk modulus of elasticity, $\mathrm{E}_{\mathrm{m}}=8.0 \times 10^{5} \mathrm{~N} \mathrm{~m}^{-2}$; frame bulk density, $\rho_{1}=30 \mathrm{~kg} \mathrm{~m}^{-3}$; frame loss factor, $\eta=0.25$; flow resistance, $\sigma=100 \times 10^{3} \mathrm{MKS}$ Rayls $\mathrm{m}^{-1}$; structure factor, $\epsilon=6.0$; porosity, $h=0.9$; membrane superficial mass, $m_{s}=0.045 \mathrm{~kg} \mathrm{~m}{ }^{-2}$. Experience suggests that these values are appropriate for conventional noise control foams. These parameters 
are used in all subsequent calculations, and, when an airspace is present, its depth, $\Delta$, is always $1 \mathrm{~mm}$.

The solid line shows the impedance of the open faced layer; it is quite typical of a finite depth layer of porous material. The addition of a loose membrane (i.e., separated from the foam by $1 \mathrm{~mm}$ ) has no effect on the real part of the impedance (except for a very small change due to the shift of surface location). The imaginary part of the impedance is altered by the addition of the mass reactance which give the reactance an overall positive linear slope.

As expected, the situation is very different when the film is bonded to the foam surface. The real part of the impedance is essentially that of the frame itself (having a mean value of about $\left.12 \rho_{\mathrm{O}} c\right)$ and is everywhere greater than either of the other two cases. The reactance shows the $-\cot (\mathrm{kl})$ shape characteristic of a finite depth of homogeneous elastic material, and it is given a positive slope by the addition of the membrane.

This slide emphasizes once again that the important attribute of a film facing is not simply its mass. The addition of a membrane may produce radically different results depending on how it is applied to the surface. 
SLIDE 11

In this slide and the next, effects associated with the rear surface of a relatively stiff, partially reticulated foam layer will be described.

First, when the foam is bonded to a hard backing, it is required that both the frame and air velocities, $v_{1}$ and $v_{2}$, be equal to zero at $x=\ell$. No force conditions apply since the backing can support any finite force generated by either phase of the material. However, when the foam is separated from the backing by a small air gap, then the conditions which apply at $x=l$ are those for an open surface: i.e., conservation of volume velocity and the force conditions shown in slide 5. The important fact to note is that the two cases do not become equivalent as $\Delta$ goes to zero; when the foam is not bonded to the backing it is only required that $w_{1}(1-h)+v_{2} h=0$ at the rear surface of the foam. Since acoustic displacements are on the order of a micron, this effect will operate, even if $\Delta$ appears to be negligibly small, so long as the foam igs not either bonded to the backing surface or forced against it by an externally applied force.

The difference in rear surface boundary conditions would not be significant save for the fact that in relatively stiff, partially reticulated foams the high impedance frame wave carries a significant part of the wave motion. This wave may see even a very thin air gap as approaching a pressure release surface. This impression is reinforced by calculations which show that the imclusion of "a 
small air gap between foam and backing alters the imaginary part of the surface normal impedance from a $-\cot (k l)$. form to a form much closer to the $\tan (\mathrm{kl})$ characteristic expected for a layer backed by a pressure release surface. The net effect of this transformation is to shift layer resonances to lower frequencies when the air gap is added. These effect's are especially noticeable when the front surface of the foam is sealed by a membrane since frame motion is well excited by the nature of the equal velocity boundary conditions.

\section{$\underline{\text { SLIDE } 12}$}

This slide shows the surface normal impedance of a film-faced foam layer (the film is bonded to the foam) in two configurations: with the foam bonded to a hard backing so that no motion at $x=\ell$ is allowed, and separated from the backing by an air gap, so that relative air-frame motion is allowed at $x=\ell$.

The effects are as described in the last slide, the principal one being the shift of layer resonance features to significantly lower frequencies. Specifically, the frequency of the first positive-going zero crossing of the reactance, which approximately locates the first peak in the absorption coefficient, is lowered dramatically by the presence of the air gap. This explains the results shown in slide 3 at the beginning of the talk. 


\section{SLIDE 13}

Illustrated here are the variety of different absorption results possible with different air space configurations in a filmfaced foam layer. Note that the material properties of the foam and membrane are the same in each case; the large changes are due purely to the presence or absence of $1 \mathrm{~mm}$ air gaps between the film and the foam and/or the foam and the hard backing.

The immediate conclusion from this plot is that, for this "average" type of noise control foam, the film bonded to foam bonded to hard backing case is the worst possible configuration; absorption is poor at both low and high frequencies with isolated narrow peaks in the mid-frequency range. The addition of a space behind the foam shifts this absorption pattern to lower frequencies. If the only concern were to absorb sound in a relatively narrow band of low frequencies then this would appear to be the best configuration. However, as a consequence of the direct bonding of the film to the foam, high frequency absorption is not good. The high frequency absorption is of course greatly improved when a space is included between the film and the foam, a consequence of the reduced surface impedance in this case. In addition, the low frequency absorption is significantly better with the loose membrane than when the film is bonded to the foam and the foam to the backing. In the loose membrane configuration, the rear surface boundary conditions do not have a very dramatic effect (presumably since the frame wave is not so well excited in this case) but there is still some shift to, lower frequencies produced by the presence of an air gap between foam and 
backing. It is clear that neither of the loose film configurations produce the very low frequency absorption of the

$\mathrm{film} / \mathrm{foam} / \mathrm{space} / \mathrm{backing}$ configuration; compared to the latter, however, the high frequency absorption of the loose film configuration is much improved. It is suggested here that unless absolute performance at very low frequencies is a priority, the film/space/foam/space/backing arrangement will give the best overall compromise between high and low frequency absorption.

\section{$\underline{\text { SLIDE } 14}$}

This slide highlights the influence of the air spaces. The film/foam/backing arrangement is a treatment frequently used in practice; it is nevertheless far from being an optimum arrangement. This slide shows that the noise control performance of film-faced foam may be greatly enhanced by including air spaces between both the film and the foam, and the foam and the backing.

\section{SLIDE 15}

For purposes of completeness, the effect of the rear surface boundary conditions on an unfaced foam layer is shown here. As expected there is some shift to lower frequencies produced by the insertion of a gap between foam and backing, but the effect is not so dramatic as in the bonded film facing case since the frame wave is not so important in the present case. Nevertheless, the frequency of the first absorption peak is lowered by almost an octave. 


\section{SLIDE 16}

Part of the intention in this paper was to make clear the fact that the action of a film facing is not due simply to its mass, but also depends on its mounting. This is not to say that the mass of the membrane is unimportant but simply to suggest that a film-faced layer of foam does not behave purely like a single degree of freedom mechanical oscillator as is sometimes imagined. Specifically, as a rule the shift of the absorption peak to lower frequencies caused by increasing the membrane mass is not directly proportional to the $\left(m_{s}\right) \frac{1}{2}$. Note by comparing cases 2 and 4 that a ten-fold increase in membrane mass lowers the first absorption peak from $900 \mathrm{~Hz}$ to $600 \mathrm{~Hz}$ rather than to $300 \mathrm{~Hz}$ as a simple oscillator model might suggest.

The other interesting feature of these results is that when a $0.015 \mathrm{~kg} \mathrm{~m}^{-2}$ membrane is used in the $\mathrm{film} / \mathrm{space} /$ foam/space/backing configuration the results are as good or better for all practical purposes than the unfaced foam at all frequencies below $10 \mathrm{kHz}$. It is commonly supposed that the addition of a membrane to the surface of a foam layer necessarily entails a significant loss of high frequency absorption. These results show that this need not be the case if the film and foam are used in an appropriate fashion. It should be noted that a $0.015 \mathrm{~kg} \mathrm{~m}^{-2}$ membrane is not impracticably light; such membranes are currently available on foams supplied by a number of noise control material suppliers. 


\section{SLIDE 17}

In addition to the observation that the action of a film facing on a foam layer is not due purely to its mass, the conclusions are as shown on this slide. The feature which unites the various conclusions is the fact that a foam layer's performance can be markedly altered by small airspaces between the foam and the backing and between a film facing and the foam. As a rule, the conventional arrangement of $\mathrm{film}$ bonded to foam bonded to backing gives the worst results of all the possible configurations. This work has suggested that unless the absorption of narrow bands of low frequency noise is the sole objective, the best overall treatment features a film facing with air gaps between the film and the foam and between the foam and the backing. The air spaces need not be of large depth and so they do not significantly increase the depth or volume of the treatment. 


\section{REFERENCES}

1. J.S. Bolton and E. Gold 1985. Paper presented at the 109th meeting of the Acoustical Society of America, Austin, Texas, April 8-12, 1985. One-dimensional wave propagation in relatively. stiff, partially reticulated acoustical foams.

2. J.S. Bolton 1984 Ph.D. Thesis University of Southampton, Institute of sound and Vibration Research. Cepstral techniques in the measurement of acoustic reflection coefficients, with applications to the determination of acoustic properties of elastic porous materials.

3. R.F. Lambert 1983 Journal of the Acoustical Society of America 73, 1131-1138. Propagation of sound in highly porous open-cell elastic foams.

4. R.F. Lambert 1983 Journal of the Acoustical Society of America 73, 1139-1146. Surface acoustic admittance of highly porous open-cell, elastic foams. 


\title{
NORMAL INCIDENCE ABSORPTION
} PROPERTIES OF SINGLE LAYERS

\author{
OF ELASTIC POROUS MATERIALS
}

$$
\text { - . - o } 00 \text { o - . . }
$$

J. S. Bolton: Ray W. Herrick Laboratories

\author{
Purdue University
}

HERRICK LABS / PURDUE UNIVERSITY 


\section{TYPE OF FOAM STUDIED}

Industrial grade polyurethane foam most often used in noise control applications is RELATIVELY STIFF and PARTIALLY RETICULATED

Relatively stiff:

Static Bulk Modulus of

Elasticity $\geq \rho_{0} c^{2}$

Partially reticulated:

Foam cells are partially closed by residual membranes.

\section{PREVIOUS WORK}

Most research has focused on fully reticulated (i.e., fully open cell) foam. Residual inter-cell membranes are removed by chemical or other means.

These foams are: - expensive

- relatively limp

- used only in special applications:

e.g., anechoic chambers

HERRICK LABS / PURDUE UNIVERSITY 


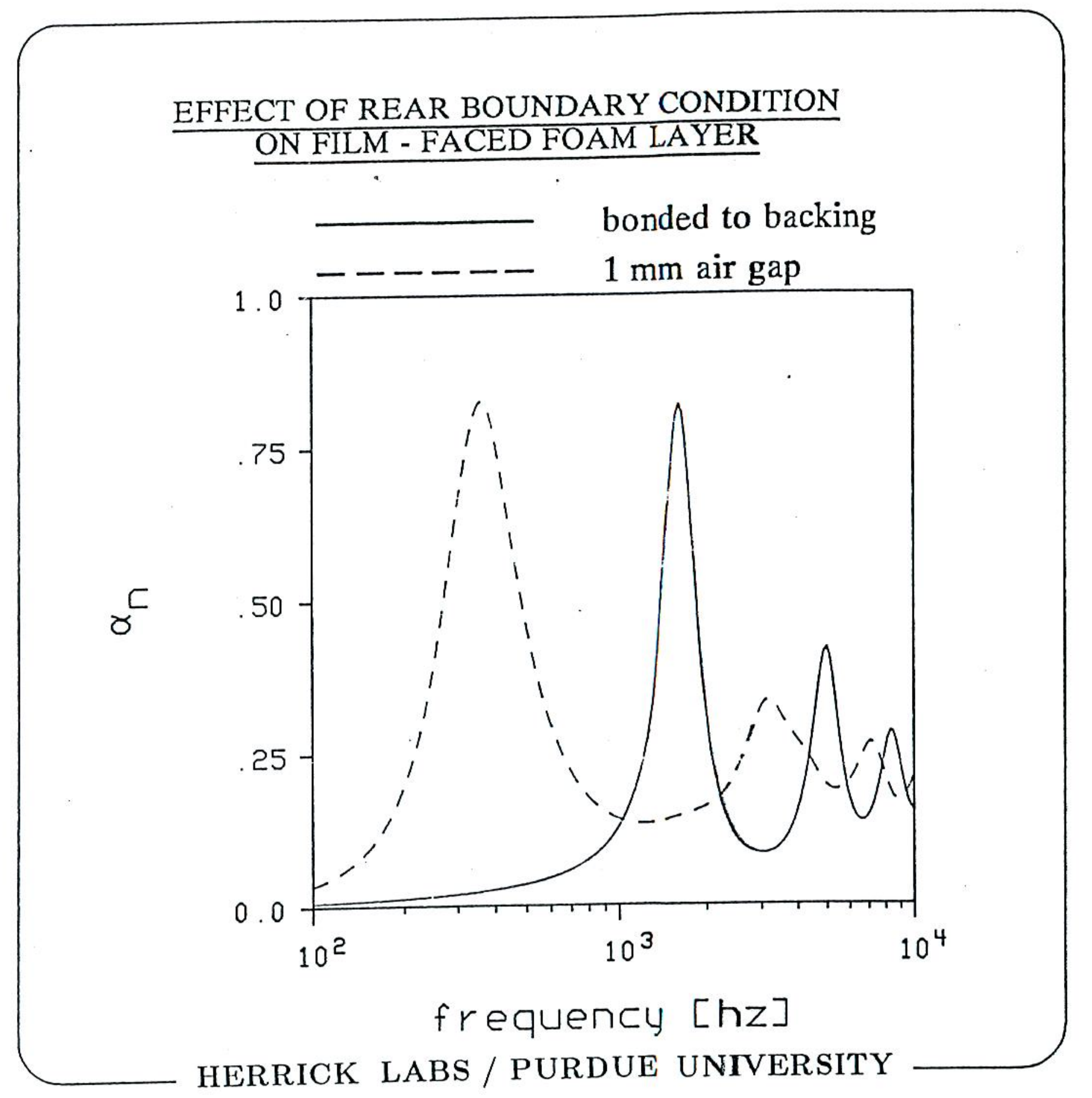

SLIDE 3 


\section{WAVE PROPAGATION IN ELASTIC POROUS MATERIALS}

WRITE: One-dimensional continuity and force equations for the solid phase of the foam (the "frame") and for the air component

RESULT: Expressions for air and frame stresses and velocities of form: e.g., Frame velocity

$$
v_{1}=j \omega\left(C_{1} e^{\gamma_{1} x}+C_{2} e^{-\gamma_{1} x}+C_{3} e^{\gamma_{2} x}+C_{4} e^{-\gamma_{2} x}\right)
$$

Forward and backward - going waves of two types

"FRAME WAVE" and "AIRBORNE WAVE"

$\mathrm{C}_{1}$ to $\mathrm{C}_{4}$ determined by boundary conditions

HERRICK LABS / PURDUE UNIVERSITY 


\section{BOUNDARY CONDITIONS}

OPEN SURFACE:

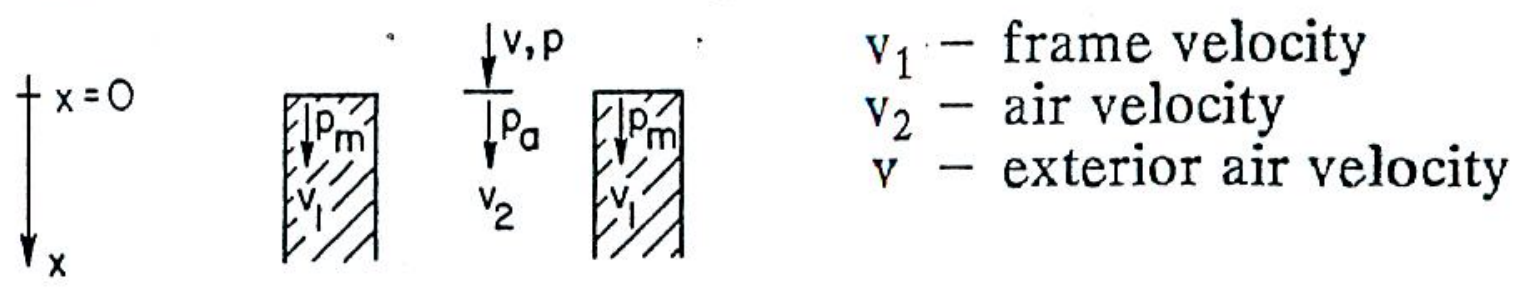

Velocity: $\mathrm{v}=\mathrm{v}_{1}(1-\mathrm{h})+\mathrm{v}_{2} \mathrm{~h}$, where $\mathrm{h}=$ porosity

Force: $\mathrm{p}_{1}=\mathrm{p}(1-\mathrm{h}), \mathrm{p}_{2}=\mathrm{ph}$

Where: $\mathrm{p}_{1}=(1-\mathrm{h}) \mathrm{p}_{\mathrm{m}}=$ force/unit area on solid component

$$
\begin{aligned}
& \mathrm{p}_{2}=h \mathrm{p}_{\mathrm{a}}=\text { force/unit area acting on air component } \\
& \mathrm{p}=\text { exterior air pressure }
\end{aligned}
$$

MEMBRANE:

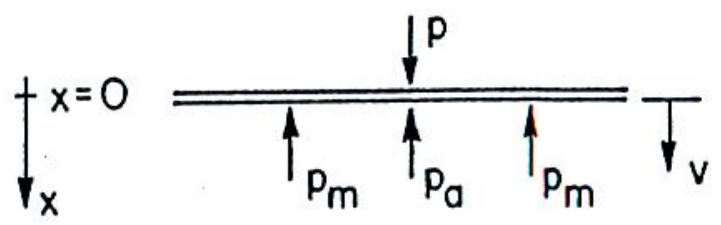

Force: $p-p_{1}-p_{2}=m_{s} \frac{d v}{d t}$ where $m_{s}=$ mass/area

$$
=j \omega \mathrm{m}_{\mathrm{s}} \mathrm{v} \text { (single frequency) }
$$

HERRICK LABS / PURDUE UNIVERSITY 


\section{BOUNDARY CONDITIONS}

BONDED MEMBRANE:

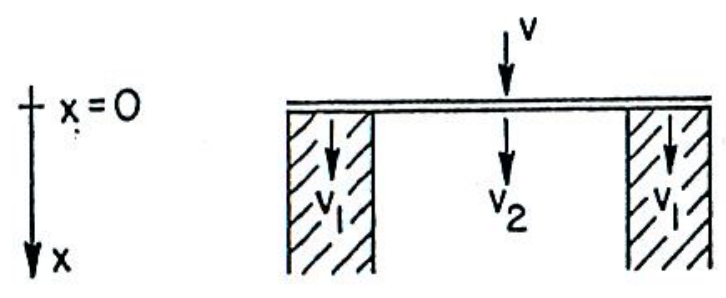

Velocity: $\mathrm{v}_{1}=\mathrm{v}, \mathrm{v}_{2}=\mathrm{v}$

Force: $\quad p-p_{1}-p_{2}=m_{s} \frac{d v}{d t}=j \omega m_{s} v$

UNBONDED MEMBRANE:
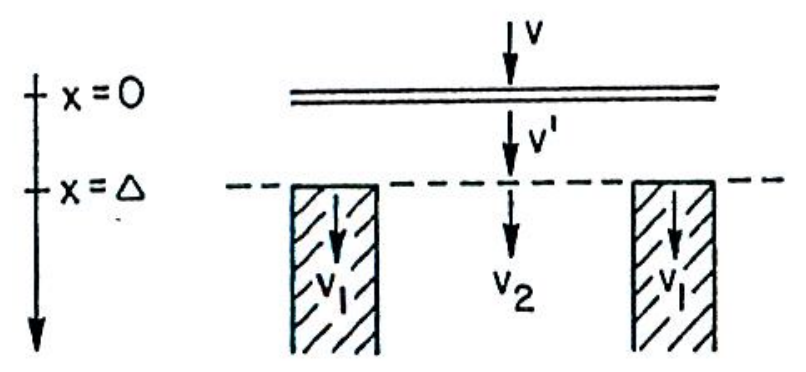

At $\mathrm{x}=0-$ Velocity: $\mathrm{v}=\mathrm{v}^{\prime}$

$$
\text { Force: } \quad p-p^{\prime}=j \omega m_{s} v
$$

$$
\begin{aligned}
\text { At } \mathrm{x}=\Delta-\text { Velocity: } \mathrm{v}^{\prime}=\mathrm{v}_{1}(1-\mathrm{h})+\mathrm{v}_{2} \mathrm{~h} \\
\text { Force: } \mathrm{p}_{1}=\mathrm{p}^{\prime}(1-\mathrm{h}), \mathrm{p}_{2}=\mathrm{p}^{\prime} \mathrm{h}
\end{aligned}
$$

HERRICK LABS / PURDUE UNIVERSITY 


\section{SURFACE IMPEDANCE}

AT OPEN SURFACE:

$$
\begin{aligned}
& f_{x}^{x=0}
\end{aligned}
$$

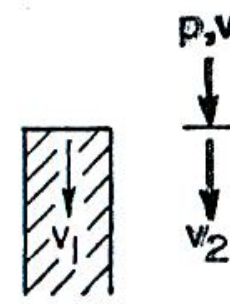

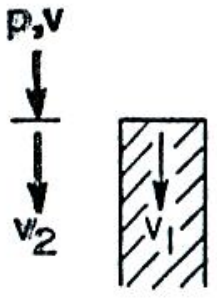

where: $\mathrm{z}_{1}=\mathrm{p}_{1} / \mathrm{v}_{1}$ and $\mathrm{z}_{2}=\mathrm{p}_{2} / \mathrm{v}_{2}$

Note: Frame and Air Impedances add in parallel 


\section{SURFACE IMPEDANCE}

AT SEALED SURFACE:
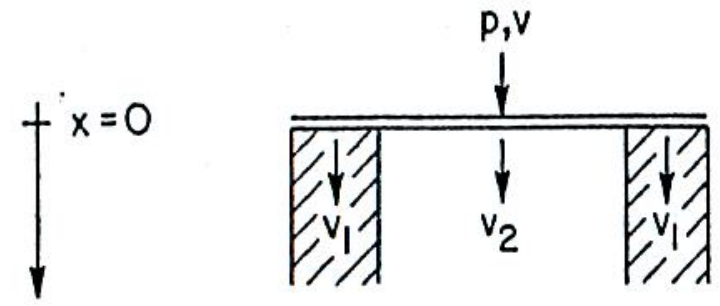

$$
z=\frac{p}{v}=\frac{p_{1}+p_{2}+j \omega m_{s} v}{v}=z_{1}+z_{2}+j \omega m_{s}
$$

Note: "Frame", "Air" and Membrane Impedances add in series (even if membrane has zero mass) 


\section{SURFACE IMPEDANCE}

UNBONDED MEMBRANE:

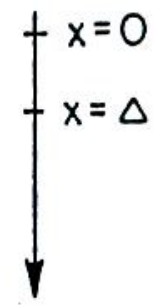

$$
z=\frac{p}{v} \simeq z_{o}+j \omega m_{s} \text { when } \Delta \rightarrow 0
$$
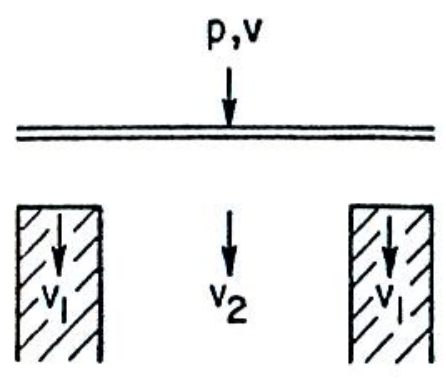

Note: Open surface impedance and membrane impedance add in series. 


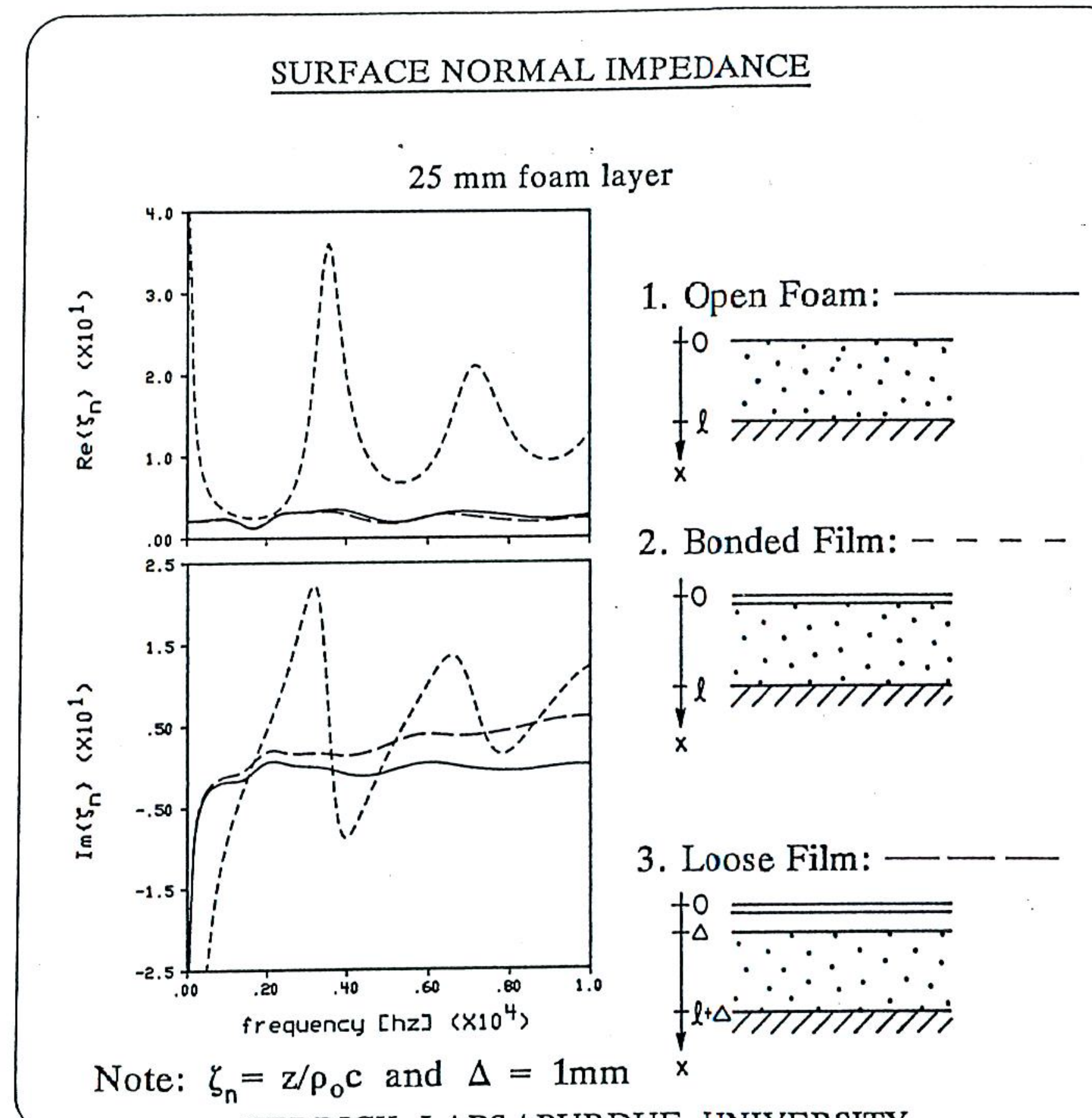

HERRICK LABS / PURDUE UNIVERSITY 


\section{REAR SURFACE BOUNDARY CONDITIONS}

Bonded

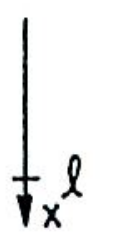

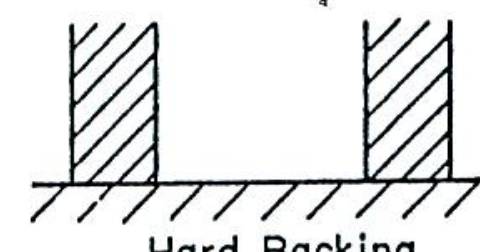

Hard Backing

$$
\mathrm{v}_{1}=\mathrm{v}_{2}=0
$$

Unbonded

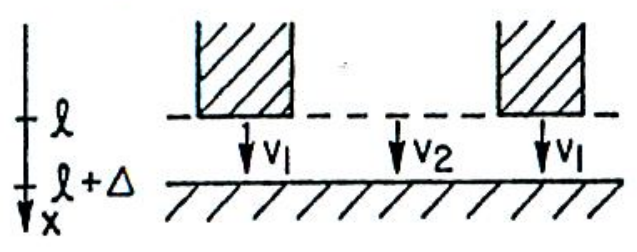

As $\Delta \rightarrow 0$

$$
\mathrm{v}_{1}(1-\mathrm{h})+h \mathrm{v}_{2}=0
$$

- These two cases are not equivalent

- In relatively stiff, partially reticulated foam high impedance frame wave carries significant energy

- This wave sees thin air space as "pressure release" surface

- Shifts absorption peaks to lower frequencies: i.e., $\mathrm{z} \simeq \tan (k l)$ rather than $\cot (k l)$. 


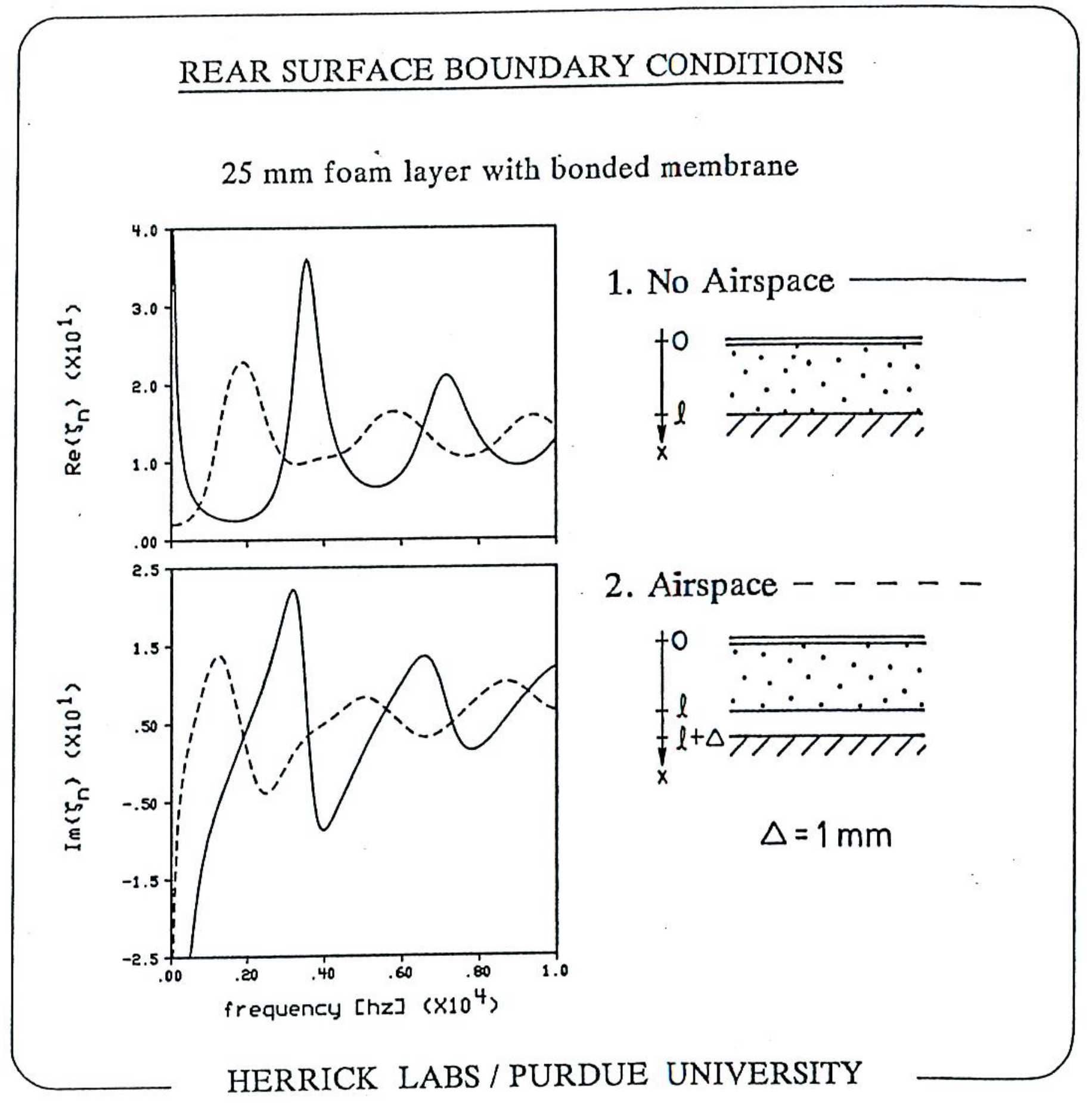

SLIDE 12 


\section{NORMAL INCIDENCE ABSORPTION}

Effect of Airspaces at front and rear

1. Film/Foam/Backing

2. Film/Space/Foam/Backing

3. Film/Foam/Space/Backing

4. Film/Space/Foam/Space/Backing _-

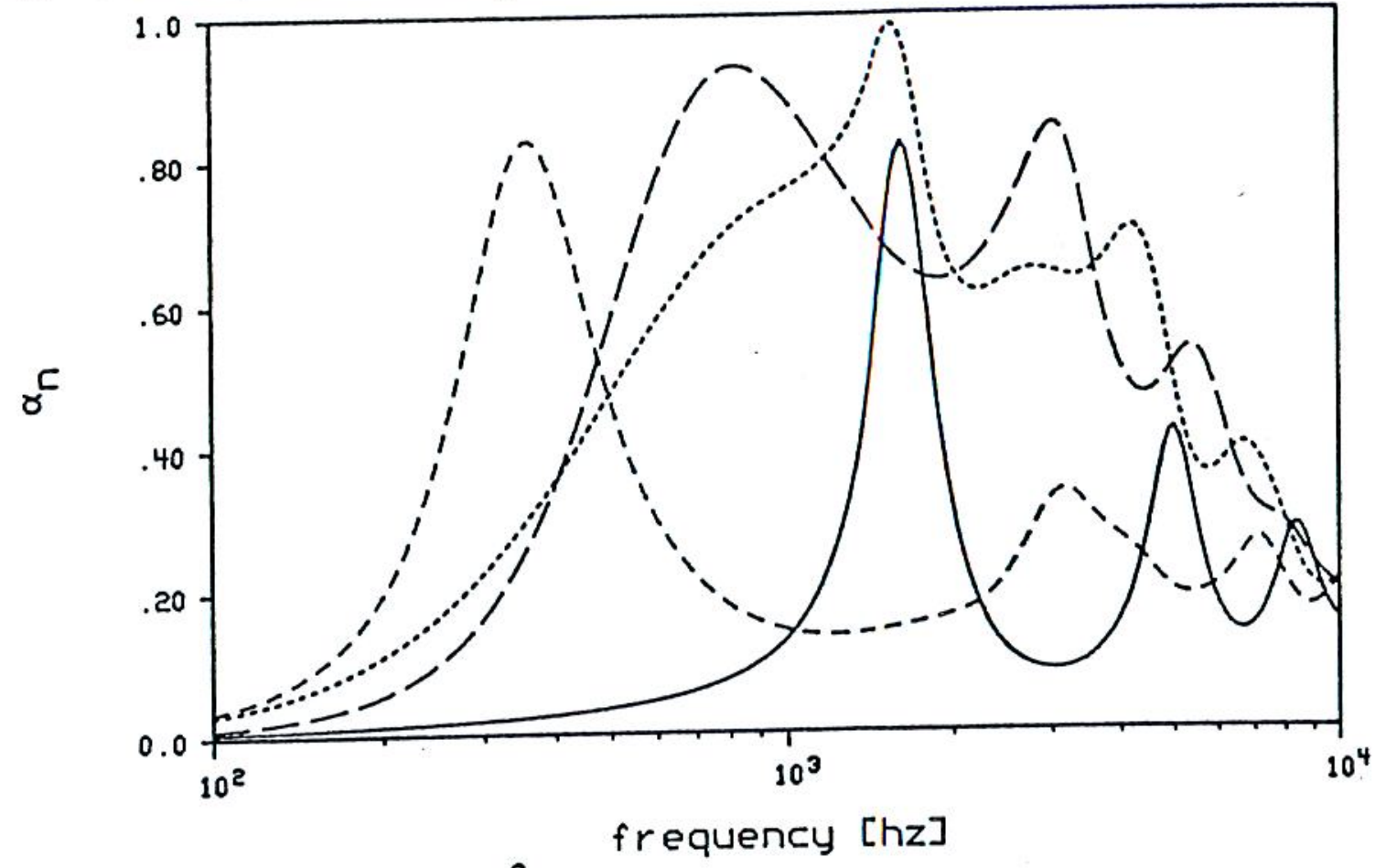

Foam - $25 \mathrm{~mm}, 30 \mathrm{~kg} / \mathrm{m}^{3}$

Membrane $-0.045 \mathrm{~kg} / \mathrm{m}^{2}$

Airspaces - $1 \mathrm{~mm}$

HERRICK LABS / PURDUE UNIVERSITY

SLIDE 13 


\section{NORMAL INCIDENCE ABSORPTION}

Effect of Airspace at.front and rear

1. Film/Foam/Backing

2. Film/Space/Foam/Space/Backing _...-

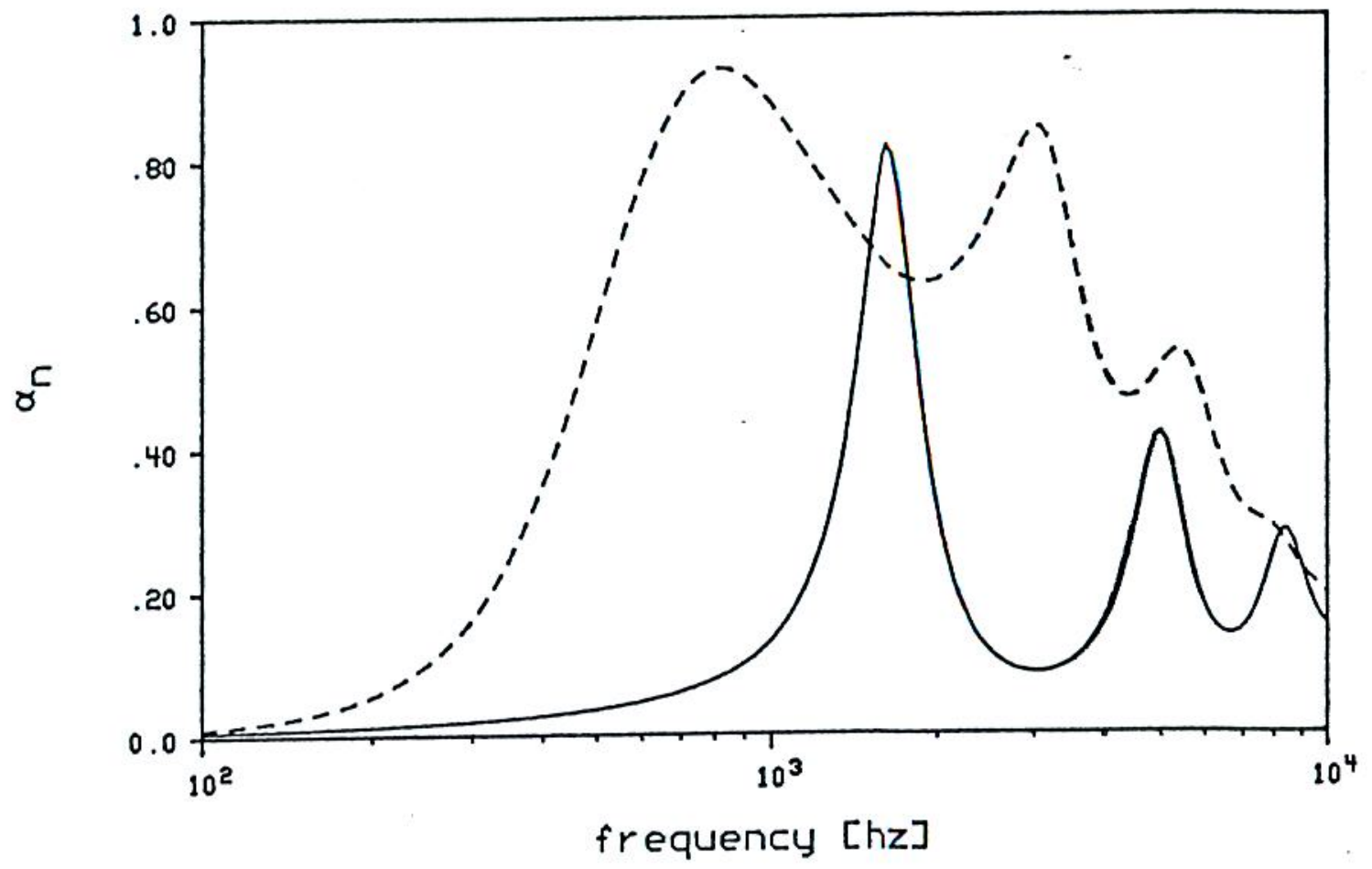

Foam - $25 \mathrm{~mm}, 30 \mathrm{~kg} / \mathrm{m}^{3}$

Membrane $-0.045 \mathrm{~kg} / \mathrm{m}^{2}$

HERRICK LABS / PURDUE UNIVERSITY

SLIDE 14

$=$ 


\section{NORMAL INCIDENCE ABSORPTION}

1. Foam/Backing

2. Foam/Space/Backing _

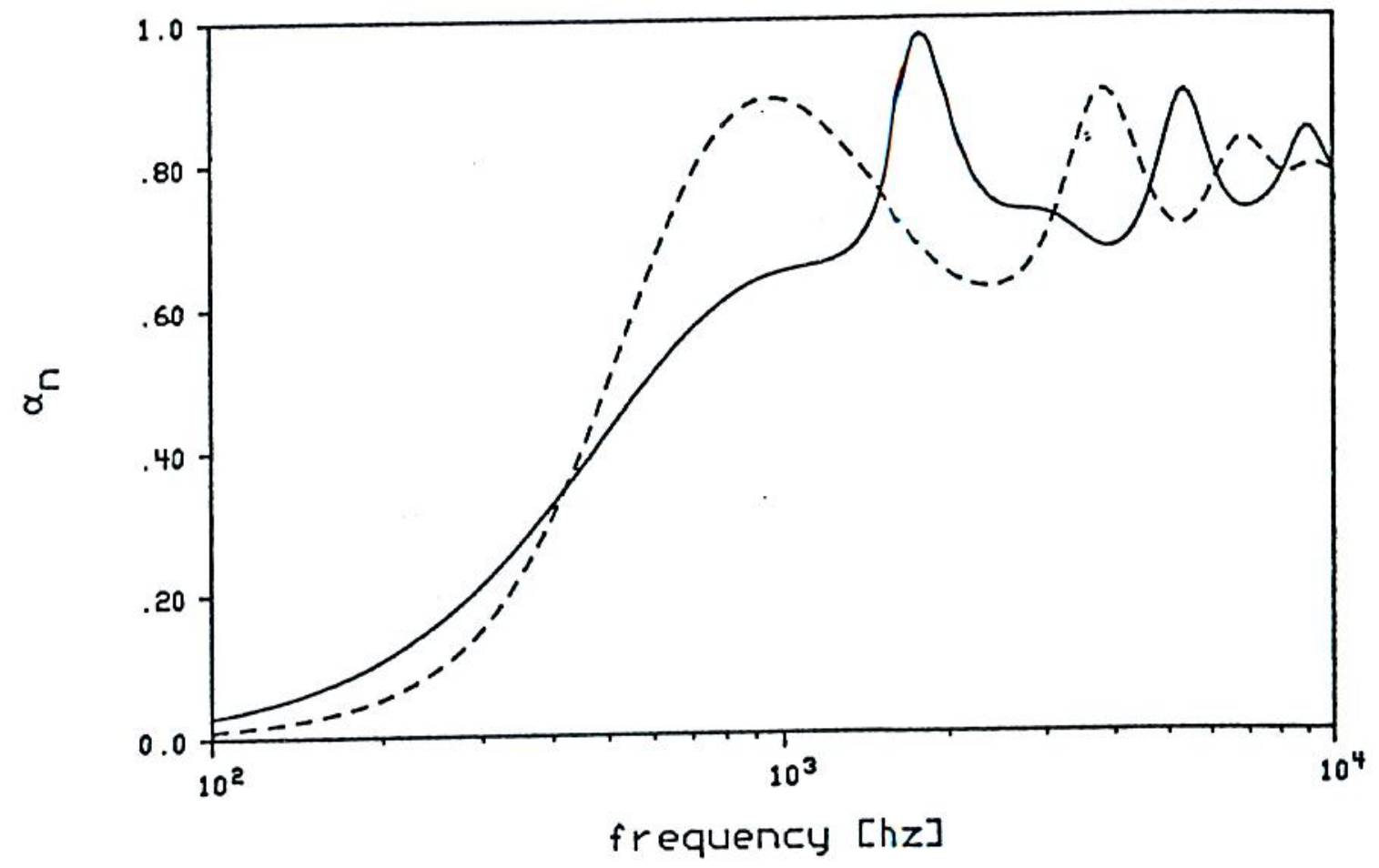

Foam $-25 \mathrm{~mm}, 30 \mathrm{~kg} / \mathrm{m}^{3}$

Airspace - $1 \mathrm{~mm}$

HERRICK LABS / PURDUE UNIVERSITY

SLIDE 15 


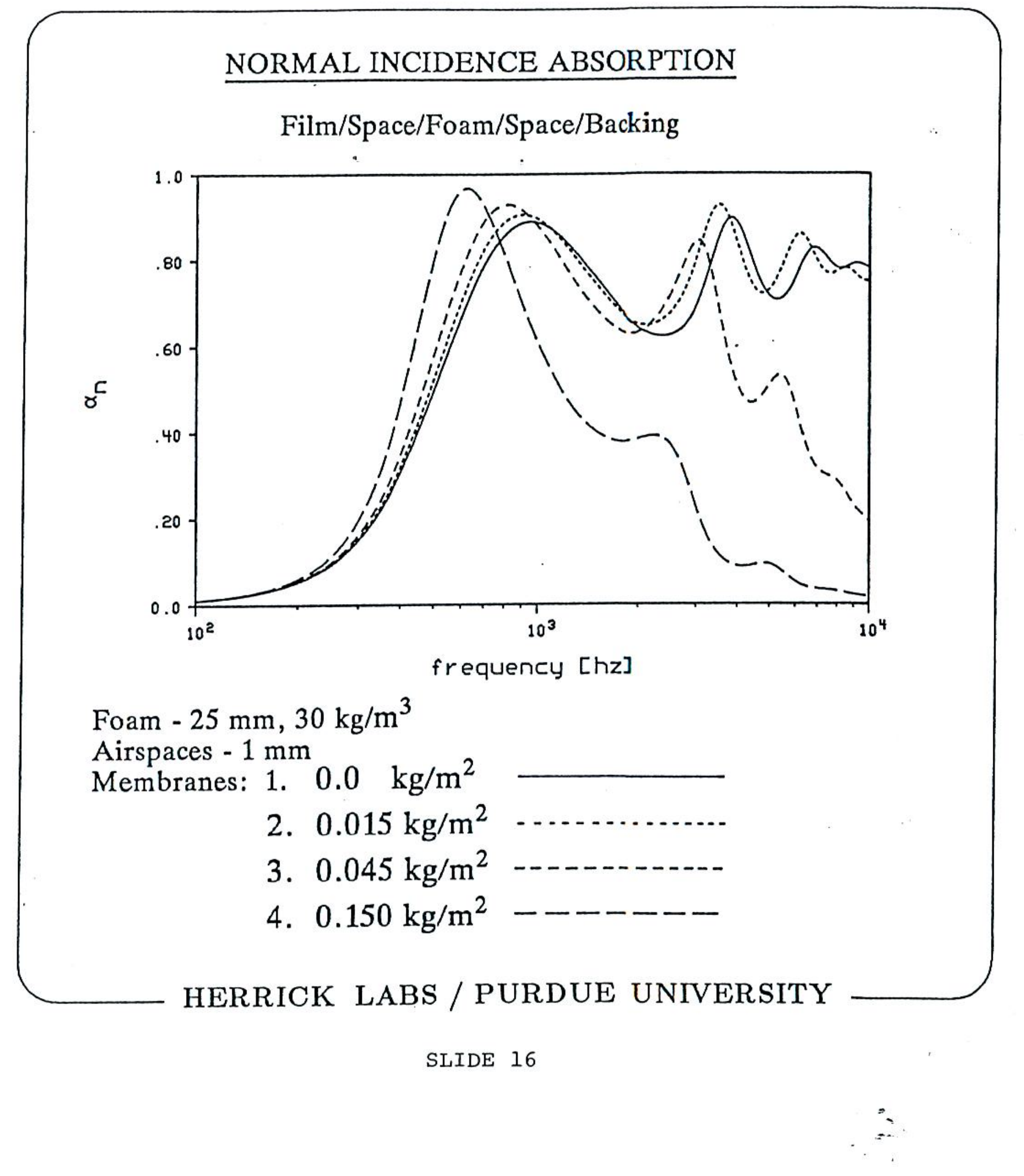




\section{CONCLUSIONS}

FOR RELATIVELY STIFF, PARTIALLY RETICULATED FOAMS:

1. "Loose" surface membrane gives better overall performance than bonded membrane (except at very low frequencies).

2. Small air space behind foam layer enhances low frequency performance with or without front membrane.

3. Light, loose membrane on foam with thin backing space gives performance essentially as good as open face foam while protecting foam. 
